\title{
ANALISA TINGKAT BAHAYA DAN KERENTANAN BENCANA GEMPA BUMI DI WILAYAH NUSA TENGGARA TIMUR (NTT)
}

\author{
Ni Made Rysnawati ${ }^{1}$, I Ketut Sukarasa ${ }^{1}$, Ida Bagus Alit Paramarta ${ }^{1}$
}

${ }^{1}$ Jurusan Fisika, Fakultas Matematika dan Ilmu Pengetahuan Alam, Universitas Udayana, Kampus Bukit Jimbaran, Badung, Bali Indonesia 80361.

${ }^{2}$ Instalasi Radioterapi RSUP Sanglah Denpasar

Email : ketut_sukarasa@unud.ac.id

\begin{abstract}
Abstrak
Nusa Tenggara Timur merupakan wilayah di Indonesia yang masuk dalam kategori rawan akan bahaya gempa bumi, karena diapit oleh 2 zona penyebab gempa bumi, (zona subduksi di sebelah selatan dan patahan naik busur belakang di sebelah utara). Wilayah ini juga rentan karena kepadatan penduduk yang tinggi. keadaan ini dapat mengancam keselamatan jiwa serta harta benda penduduk, sehingga perlu adanya penelitian untuk menganalisa tingkat bahaya dan kerentanan gempa bumi di wilayah Nusa Tenggara Timur. Untuk mengidentifikasi tingkat bahaya dan kerentanan bencana gempa bumi dalam penelitian ini dilakukan berdasarkan 2 faktor : faktor bahaya dengan indikator percepatan getaran tanah maksimum (Peak Ground Acceleration = PGA), faktor kerentanan dengan indikator kepadatan penduduk perkabupaten di provinsi Nusa Tenggara Timur. Perhitungan nilai PGA dilakukan dengan menggunakan fungsi atenuasi Fukushima dan Tanaka. Dari hasil analisa data maka diperoleh tingkat bahaya gempa bumi sangat tinggi berada di Kabupaten Ende dan Alor, sedangkan tingkat kerentanan yang sangat tinggi berada di Kabupaten Sikka, Sumba Barat Daya dan Sabu Raijua.
\end{abstract}

Kata Kunci : fungsi atenuasi, PGA, Kepadatan penduduk, Bahaya, Kerentanan bencana gempa bumi.

\begin{abstract}
East Nusa Tenggara is a region in Indonesia which included in the category of hazard prone to earthquakes, because it is flanked by two earthquakes zones, (subduction zone at the south and back arc trust in the north). It is also vulnerable to earthquake disasters because of high population density. These conditions would threaten the safety of lives and property of the population, so it needs to be research to analyze the level of earthquake hazard and vulnerability in East Nusa Tenggara. For identification of the level of hazard and the vulnerability of the earthquake in this study using two factors: the danger factor with indicator Peak Ground Acceleration, vulnerability factors with indicators of population density districts in East Nusa Tenggara. The calculation of the value of PGA use attenuation function of Fukushima and Tanaka. From the calculation of the data obtained that has a very high earthquake hazard is in Ende and Alor district, while the district has a very high risk of vulnerability is in Sikka, Sumba Barat Daya and Sabu Raijua.
\end{abstract}

Keywords : the attenuation function, PGA, population density, hazzard, vulnerability earthquake disaster.

\section{PENDAHULUAN}

Gempa bumi merupakan fenomena alam yang tidak dapat diprediksi dan bisa terjadi kapan saja.Gempa bumi terjadi 32 hampir di seluruh belahan dunia termasuk di Indonesia.Nusa Tenggara Timur merupakan wilayah di Indonesia yang masuk dalam kategori rawan gempa. Hal ini dikarenakan 
daerah Nusa Tenggara Timur diapit oleh 2 zona penyebab gempa bumi, yaitu wilayah selatan merupakan tempat bertemunya dua lempeng yaitu, lempeng Eurasia dan IndoAustralia secara subduksi, dan dibagian sebelah utara terdapat patahan naik busur belakang (back arc thrust) ${ }^{[3]}$. Goncangan tanah yang terjadi pada setiap kejadian gempa bumi dapat dianalisis melalui nilai percepatan getaran tanah (PGA) pada suatu tempat. Besar kecilnya nilai percepatan getaran tanah tersebut menjadi faktor yang dapat menunjukkan tingkat bahaya bencana gempa bumi ${ }^{[2]}$. Faktor untuk menentukan tingkat kerentanan bencana gempa bumi yakni: faktor sosial (kepadatan penduduk). Secara demografi, wilayah NTT memiliki tingkat pertumbuhan penduduk yang pesat yaitu $2,07 \%$ per tahun dengan jumlah total kepadatan penduduk 2469 jiwa/ $/ \mathrm{km}^{2}$. Daerah dengan kepadatan penduduk tinggi berada di Kabupaten Sumba Barat Daya dengan kepadatan penduduk sebanyak 212 jiwa/ $/ \mathrm{km}^{2[5]}$. Berdasarkan uraian di atas maka wilayah Nusa Tenggara Timur merupakan daerah rawan akan bahaya dan kerentanan bencana gempa bumi, yang dapat mengancam keselamatan jiwa dan harta penduduk di wilayah tersebut.

\section{TINJAUAN PUSTAKA}

\subsection{Konsep Bencana}

1. Bahaya (hazards)

Bahaya adalahfenomena alam atau buatan yang berpotensi merusak kehidupan manusia, kerugian materi, serta kerusakan lingkungan ${ }^{[1]}$.

\section{Kerentanan (vulnerability)}

Kerentanan (vulnerability) adalah keadaan dari suatu masyarakat yang mengarah pada ketidakmampuan dalam menghadapi suatu ancaman bahaya ${ }^{[1]}$.

\subsection{Percepatan Getaran Tanah Maksimum (Peak Ground Accelaration)}

Percepatan getaran tanah maksimum adalah nilai terbesar percepatan tanah pada suatu tempat akibat getaran gempa bumi dalam periode waktu tertentu.Fungsi atenuasi merupakan fungsi korelasi intensitas gerakan tanah, dan magnitude, serta jarak dari suatu titik dalam daerah radius sumber gempa. Wilayah Indonesia sendiri belum memiliki rumusan yang pasti mengenai persamaan fungsi atenuasi, sehingga dalam penelitian tugas akhir ini digunakan persamaan fungsi atenuasiFukushima dan Tanaka(1990)yang telah digunakan oleh para peneliti sebelumnya ${ }^{[4]}$. Model ini diterapkanditerapkan di wilayah Jepang yang ditulis pada Persamaan 2.1.

$$
\begin{aligned}
& \log _{10}(P G A)=0,41 M s-\log (R+0,032 * \\
& \left.10^{0.41 M s}\right)-0,0034 R+1,30
\end{aligned}
$$

Dimana, Ms adalah magnitudo surface, $\mathrm{R}$ adalah jarak hiposenter, dan $P G A$ adalah Peak Ground Acceleratian.

\section{METODE PENELITIAN}

Penelitian ini menggunakan beberapa software dalam pengolahannya yaitu, Microsoft word 2013, Microsoft exel 2013, dan Arcview GIS 3.3. Data- data yang digunakan antara lain: data parameter gempa bumi di wilayah NTT tahun 1990 - 2015 dengan rentang skala 5-7 Ms dan kedalaman 0-100 km. Data jumlah kepadatan penduduk di tiap kabupaten/kota di provinsi NTT tahun 2013. Nilai $P G A$ dihitung terlebih dahulu adapun langkah-langkahnya adalah sebagai berikut:

1. Memilih katalog gempa bumi $\geq 5,0 \mathrm{M}_{\mathrm{S}}$.

2. Membuat peta titik perhitungandi provinsi nusa tenggara timur dengan interval $0,125^{\circ} \times 0,125^{\circ}$.

3. Menghitung jarak episenter

4. Menghitung jarak hiposenter

5. Menghitung nilai $P G A$ maksimum dari hasil perolehan nilai percepatan getaran tanah untuk tiap titik pengamatan dengan menggunakan fungsi atenuasi Fukushima dan Tanaka.

6. Pembuatan peta kontur $P G A$ maksimum.

Menentukan indikator tingkat bahaya dan kerentanan bencana gempa bumi.

1. Identifikasinya didasarkan pada 2 faktor yaitu:

a. Faktor Bahaya (hazard), dengan indikator: percepatan getaran tanah maksimum. 
b. Faktor kerentanan (vulnerability), dengan indikator: kepadatan penduduk.

2. Menghitung nilai rata-rata dan standar deviasi untuk indikator faktor bahaya dan kerentanan.

3. Hitung nilai baku dengan menggunakan model standarisasi Davidson et al (1997: 142).

4. Membuat peta tingkat bahaya dan tingkat kerentanan gempa bumi dengan menggunakanbantuan software Arcview GIS 3.3

\section{HASIL DAN DATA PENGAMATAN}

\subsection{Identifikasi tingkat bahaya bencana gempa bumi}

Untuk mendapatkan gambaran secara umum mengenai tingkat bahaya bencana gempa bumi di wilayah NTT, maka dalam penelitian ini digunakan data historis pada tahun 1990 - 2015. Dengan memilih gempa dengan rentang skala magnitudo $\geq 5 \mathrm{M}_{\mathrm{S}}$ didapatkan data sebanyak 135 kejadian gempa bumi yang tersebar di wilayah NTT. Data gempa bumi yang didapat tersebut selanjutnya akan dihitung nilai $P G A$ maksimumnya di tiap titik pengamatan. Kemudian nilai $P G A$ maksimum yang diperoleh di tiap titik pengamatan tersebut dibuatkan peta kontur $P G A$ maksimumnya untuk wilayah NTT dengan menggunakan program Arcview GIS 3.3 dengan menggunakan variable data dari hasil perhitungan $P G A$ maksimal. Hasilnya dapat dilihat pada Gambar 4.1.

Pada Gambar 4.1 terlihat bahwa nilai $P G A$ maksimum di wilayah NTT berkisar 2,974 - 340,455 gal. Untuk nilai $P G A$ maksimum tertinggi berada di kabupaten Ende dan Alor. Dari nilai $P G A$ yang diperoleh tersebut selanjutnya dihitung nilai bakunya untuk menentukan indeks bahaya gempa buminya. Kemudian hasil nilai baku tersebut diklasifikasikan menjadi lima kelas yaitu sangat rendah yang memiliki rentang nilai baku antara $(0,94-2,73)$, rendah $(2,74$ $-4,52)$, sedang $(4,53-6,31)$, tinggi $(6,32-$ $8,09)$ dan sangat tinggi $(8,10-9,91)$. Dengan menggunakan bantuan program ArcviewGIS 3.3 dibuatkan peta kontur tingkat bahaya seperti pada Gambar 4.2.

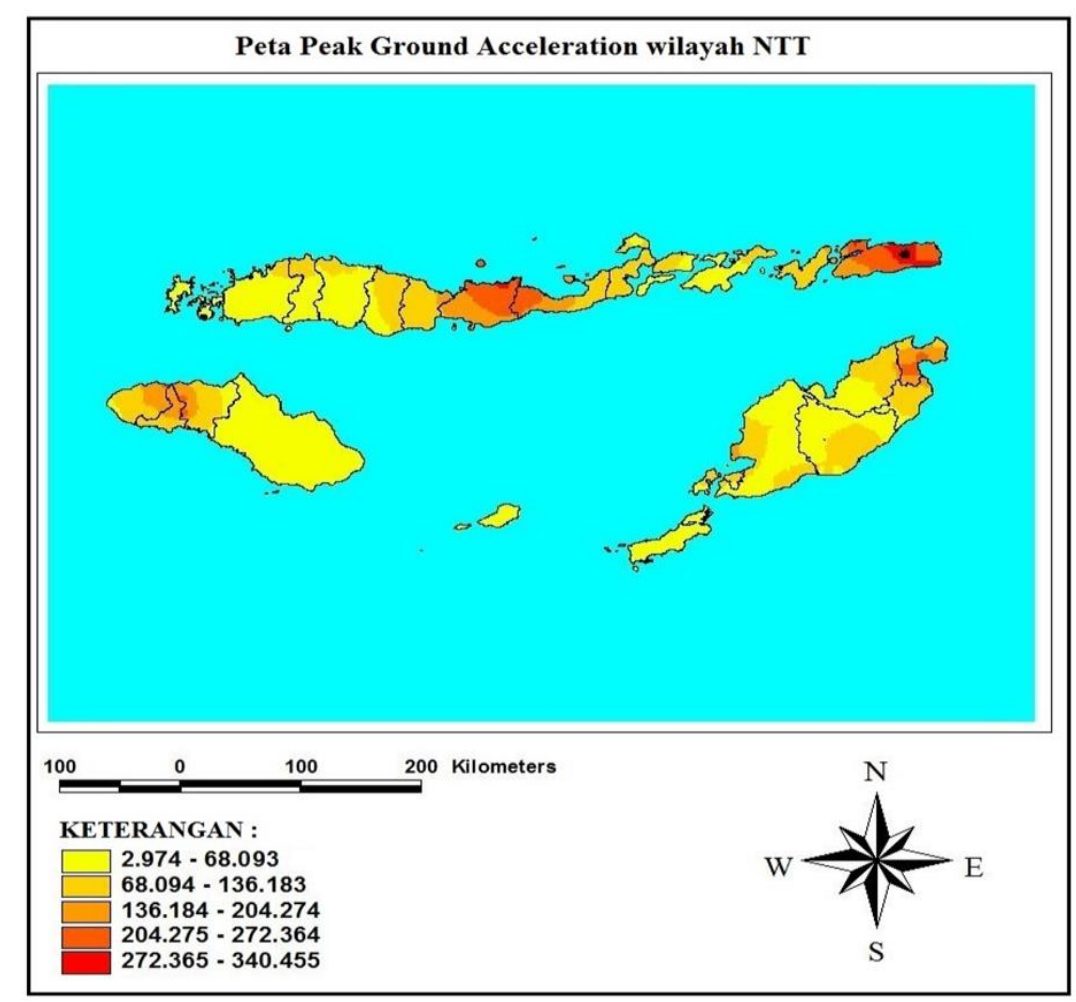

Gambar 4.1 Peta Peak Ground Acceleration Wilayah NTT 


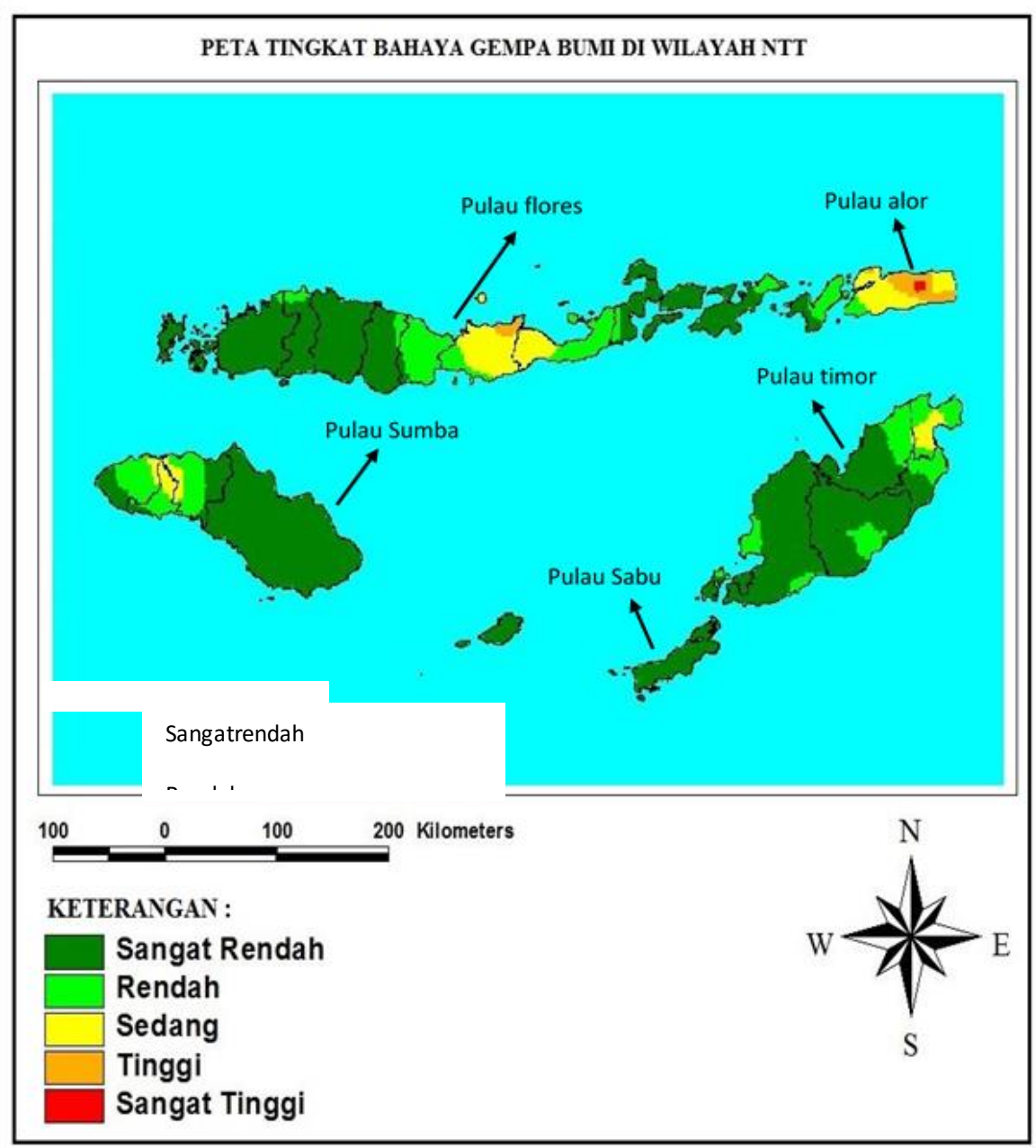

Gambar 4.2. peta tingkat bahaya bencana gempa bumi di wilayah NTT

Dari peta tingkat bahaya bencana gempa bumi di atas dapat diketahui bahwa tingkat bahaya gempa bumi tinggi berada di wilayah Pulau Alor kabupaten alor dan Pulau Flores kabupaten ende ( NTT bagian timur)

\subsection{Identifikasi tingkat kerentanan bencana gempa bumi}

Untuk mendapatkan gambaran secara umum mengenai kerentanan bencana gempa bumi, digunakan acuan data kepadatan penduduk di tiap kabupaten/kota di wilayah NTT pada tahun 2013. Tingginya kepadatan penduduk di suatu wilayah akan mengakibatkan semakin banyaknya korban jiwa dan materi yang berjatuhan saat terjadi bencana tersebut. Gambar 4.3 merupakan peta kontur kepadatan penduduk di wilayah NTT tahun 2013.

Data kepadatan penduduk perkabupaten/kota yang di dapat selanjutnya dihitung nilai bakunya untuk menentukan indeks kerentanannya. Kemudian hasil nilai baku tersebut diklasifikasikan menjadi lima kelas yaitu sangat rendah yang memiliki rentang nilai baku berkisar antara $(0,38$ $0,51)$, rendah $(0,52-1,56)$, sedang $(1,57-$ $2,33)$, tinggi $(2,34-2,97)$, dan sangat tinggi $(2,96-3,96)$. dengan menggunakan bantuan program ArcviewGIS 3.3. seperti yang ditunjukan pada Gambar 4.4. 


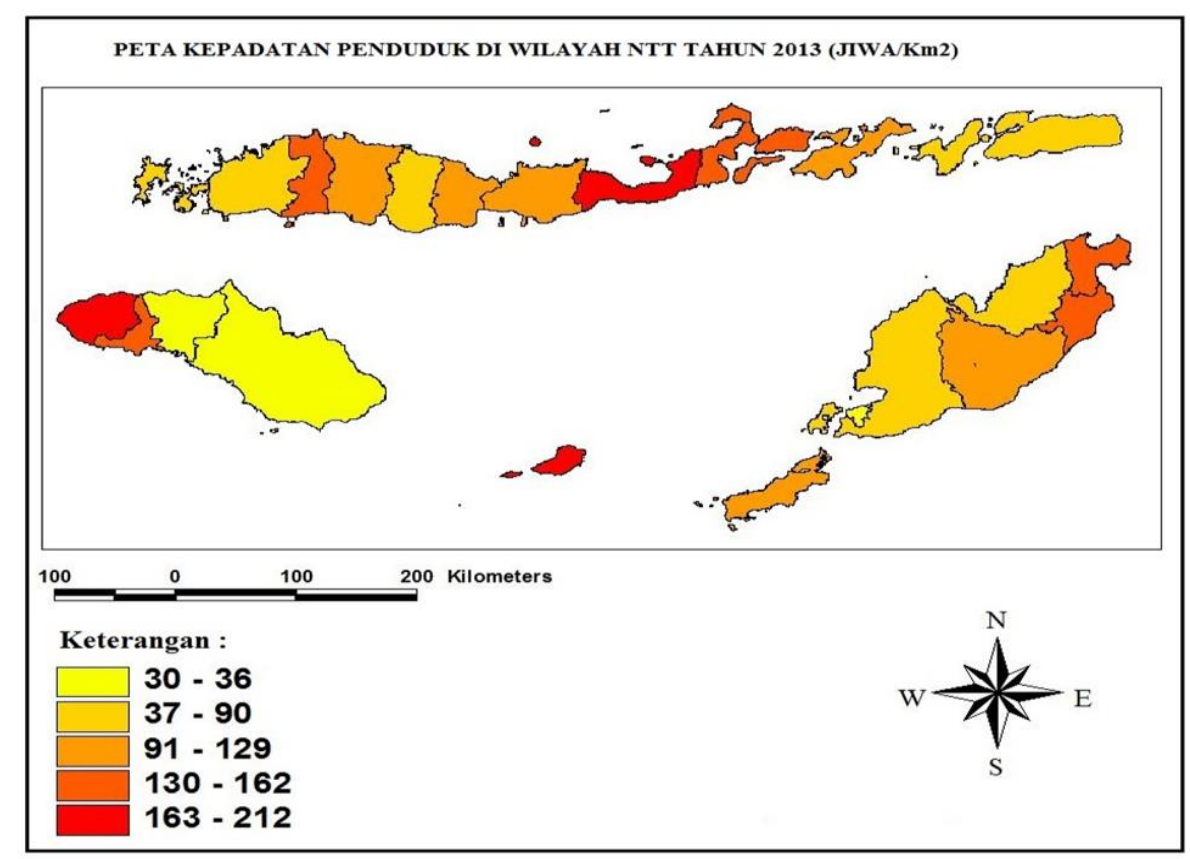

Gambar 4.3 Peta tingkat kepadatan penduduk provinsi NTT

Dari peta kontur tersebut dapat Sumba Barat Daya dan Sabu Raijua. Hal ini diketahui wilayah di NTT yang mmiliki dikarenakan ketiga kabupaten di atas tingkat kerentanan gempa bumi yang sangat merupakan daerah dengan kepadatan tinggi berada di kabupaten/kota Sikka, penduduk yang tinggi.

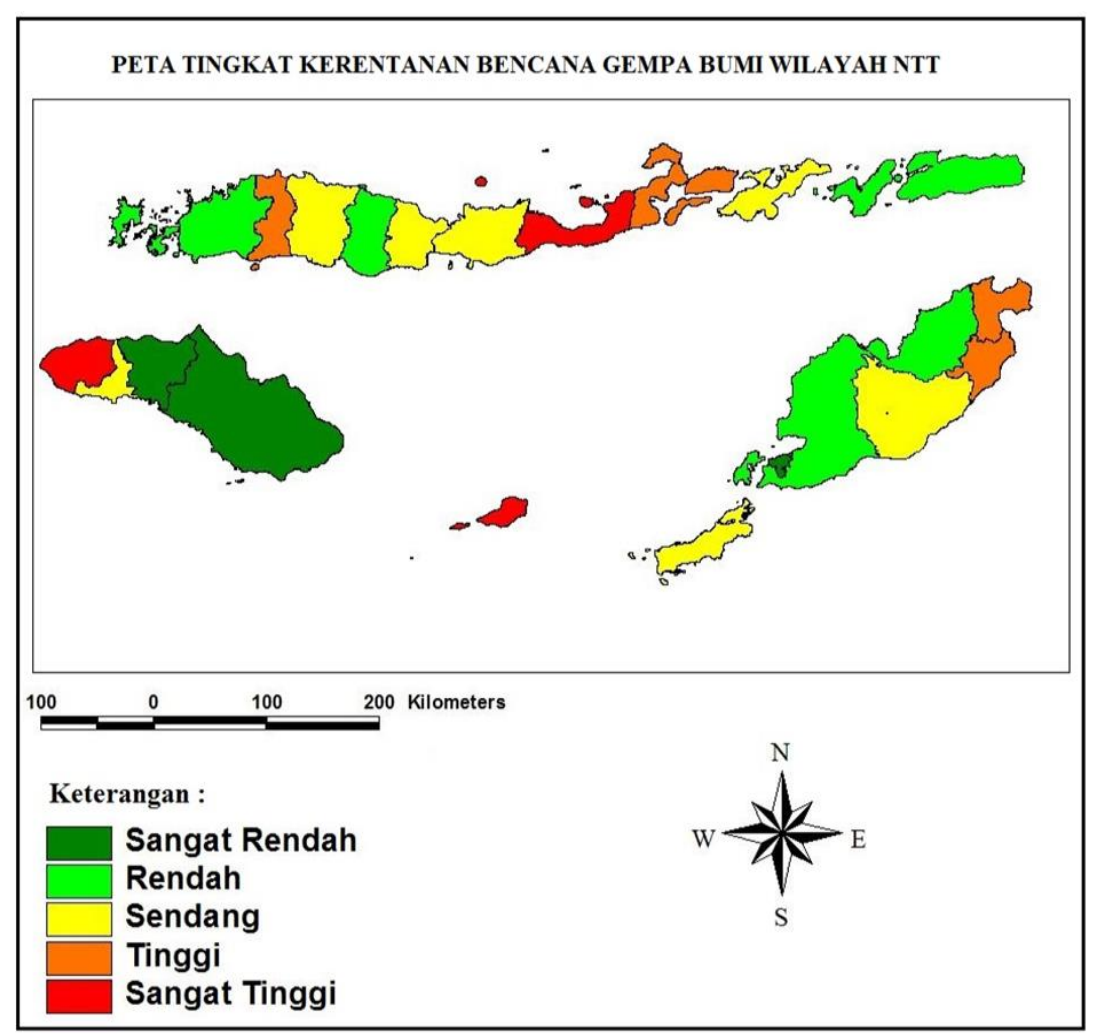

Gambar 4.4 Peta Tingkat kerentanan gempa bumi wilayah NTT 


\section{KESIMPULAN}

Berdasarkan hasil pengolahan data dan analisa tingkat bahaya dan kerentanan gempa bumi di wilayah NTT, maka dapat disimpulkan bahwa :

1. Daerah dengan tingkat bahaya bencana gempa bumi paling tinggi berada di bagian timur dan utara NTT dan paling rendah berada di bagian selatan dan barat NTT.

2. Daerah dengan tingkat kerentanan bencana gempa bumi sangat tinggi berada di Kabupaten Sikka, Sumba Barat daya, dan Sabu Raijua dan paling rendah berada di Sumba Tengah dan Kota Kupang.

3. Tingkat bahaya gempa bumi sangat tinggi berada di Kabupaten Ende dan Alor, sedangkan Tingkat kerentanan yang sangat tinggi berada di kabupaten Sikka, Sumba Barat Daya dan Sabu Raijua.

\section{DAFTAR PUSTAKA}

1. Bakornas PB.2007. Pengenalan Karakteristik Bencana dan Upaya Mitigasi di Indonesia, edisi II. Pelaksanaan Harian Badan Koordinasi Nasional Penanganan Bencana, Jakarta.

2. Badan Penanggulangan Bencana Nasional (BPBN), http://www.bnpb.go.id/pengetahuanbencana/potensi-ancaman-bencana, Diakses pada tanggal 30 Januari 2016.

3. Balai Besar Meteorologi Klimatologi dan Geofisika Wilayah III Denpasar, Gempa Bumi, http://balai3.denpasar.bmkg.go.id/tentanggempa, Diakses pada tanggal 30 Januari 2016.

4. Badan Pusat Statistik (BPS), Luas Wilayah dan Jumlah Penduduk Provinsi NTT, http://ntt.bps.go.id/linkTabelStatis/view/id /101, Diakses pada tanggal 16 Februari 2016.

5. Rudi. 2014. Analisa Tingkat Resiko Bencana Gempa Bumi di Wilayah Bali. Skripsi.Jurusan Fisika Fakultas MIPA Universitas Udayana. 